\title{
EL PIROPO: ARTEFACTO DE REPRODUCCIÓN SOCIO-CULTURAL DE MODOS DE SER A TRAVÉS DE LAS EXPERIENCIAS DE HOMBRES Y MUJERES EN SANTA CRUZ DE LA SIERRA - BOLIVIA
}

\section{A FLATTERING COMPLIMENT IN PUBLIC SPACES: A SOCIO-CULTURAL ARTIFACT THAT REPRODUCES WAYS OF BEING THROUGH MALES AND FEMALES EXPERIENCES IN SANTA CRUZ - BOLIVIA}

Paula Fernanda Lino Maldonado Centro de Investigación Social y Apoyo al Desarrollo, Santa Cruz de la Sierra. Bolivia/Bolivia paula lino92@hotmail.com

Recibido/Received: 01/09/2016

Modificado/Modified: 05/07/2017

Aceptado/Accepted: 29/09/2017

\section{RESUMEN}

El presente artículo es la síntesis de una propuesta de estudios socioculturales través de la narrativa de experiencias cotidianas en la sociedad cruceña, en donde se lo sitúa como un artefacto socio-cultural que expresa modos de ser. Es además un aporte al debate relacionado al piropo y la desmitificación del mismo como un hecho artístico o poético.

\section{PALABRAS CLAVE}

Modos de ser; significaciones; análisis de narrativa; estudios culturales; piropo en espacios públicos.

\section{SUMARIO}

1. Introducción. 2. Abordaje Metodológico. 3. Resultados. 4. Conclusión. Bibliografía.

\section{ABSTRACT}

This article is the synthesis of a sociocultural study approach through narrative common experiences in Santa Cruz society, viewed as a cultural artifact that can express ways of being. Therefore, it is a contribution for the "piropos" debate, the flattering compliments, and a demystification of it as an artistic or poetical action performed in public spaces.

\section{KEYWORDS}

Ways of being; significations; narrative analysis; cultural studies; "piropo" in public spaces.

\section{CONTENTS}

1. Introduction. 2. Methodological approach. 3. Results. 4. Conclusion. References. 


\section{INTRODUCCIÓN}

El piropo es un hecho social que forma parte de la idiosincrasia de diversas sociedades de origen mediterráneo y árabe alrededor del mundo (El País, 2011). Motivo de controversia y análisis, este hecho social ha tenido gran repercusión en estos tres planos: (1) el ideológico, asumido como violencia verbal a través de manifiestos feministas o estudios académicos; (2) el lingüístico como mensaje de cortesía o descortesía (Malaver y Gonzáles, 2008) y (3) el jurídico con promulgación de leyes.

La sociología no ha abordado la temática más allá de la descripción del fenómeno como parte del acoso callejero, en tal sentido, el presente artículo plantea la necesidad de estudiar al piropo desde el quehacer sociológico. La relevancia de este estudio es que lo posiciona como un medio o canal de expresión que nos permite conocer la configuración de modos de ser de una sociedad determinada, a través del análisis de experiencia cotidiana de ambos géneros.

\section{ABORDAJE METODOLÓGICO}

Para la presente investigación se ha optado por el método inductivo, pudiendo así comprender las significaciones masculinas y femeninas a través de la narrativa y poder interpretar el uso de la palabra en el discurso. El enfoque es comprensivo debido a la importancia atribuida a la experiencia humana contrastado con el análisis genérico proveniente de la antropología feminista de Marcela Lagarde, para poder comprender los modos de ser socioculturales otorgados al ser femenino y expresados a través de la palabra en una sociedad patriarcal u objetiva masculina (Simmel, 1930: 16).

Como primera fase, además de la observación directa del piropo en espacios públicos, se han utilizado las redes sociales para crear una plataforma en donde personas de distintas edades y de ambos géneros puedan aportar con algún piropo dicho o escuchado en la calle. Teniendo un total de 50 frases o piropos, todos ellos han sido analizados en cuanto a recursos retóricos utilizados y significancia, para conocer y comprender que los signos dicen mucho más de lo que aparentan objetivamente (Ricoeur, 2010).

La segunda fase, y siguiendo una línea metodológica cualitativa, ha consistido en profundizar las experiencias a través de la narrativa, por lo cual se han realizado 17 entrevistas abiertas a hombres y mujeres de distintas edades, desde 20 a 65 años. El análisis de los esquemas de pensamiento ha sido basado en la Teoría Fundamentada, como herramienta que permite comprender y categorizar modos de ser. Se ha utilizado el Atlas.ti como herramienta para el manejo de los datos cualitativos y su posterior categorización.

El estudio del piropo como medio de expresión de la vida cotidiana pretende responder a la necesidad de analizar las experiencias de hombres y mujeres para comprender cómo este hecho es significado (Weber, 1922) por la gente. Además del análisis fenomenológico, se deben conocer los modos de ser a través del mensaje oculto en la expresión. Para tal cometido, el entretejido teórico y metodológico se sustenta en el enfoque fenomenológico y constructivista fenomenológico (Berger y Luckmann, 1968), (Merleau - Ponty, 1993) (Schutz, 1972) y el estudio del lenguaje en tanto filosofía como sistema de símbolos, (Searle, 1969; Ricoeur, 1965; Habermas, 1999; Wittgenstein, 1988). Ambas sustentadas en el interaccionismo simbólico para la delimitación cultural (Simmel, 1930: 13) y el análisis de género y generacional (Lagarde, 2005), debido a la importancia asignada tanto a las experiencias constructoras del ser dentro de la vida cotidiana. 
Los nodos de análisis para la comprensión de modos de ser pasan por la importancia de las experiencias como constructoras en la vida cotidiana. Entendiendo como modo de ser a un esquema de pensamiento construido culturalmente que yace dentro las acciones cotidianas y la forma de percibir el mundo de una sociedad determinada. La interacción social hace que las personas conozcan su medio socio - cultural y lo signifiquen en tanto comprenden las pautas axiológicas establecidas. Tal interacción sólo es posible en la medida en la que los seres manejan un sistema de significaciones, con reglas convenidas antes de su participación en la cotidianeidad. Al respecto, se ha desarrollado un axioma teórico que engloba las categorías de análisis trascendentales para el presente estudio, en la cual se denota la importancia de la narrativa como medio de comprensión de modos de ser y significaciones:

Cuadro 1. Ilustración del axioma teórico

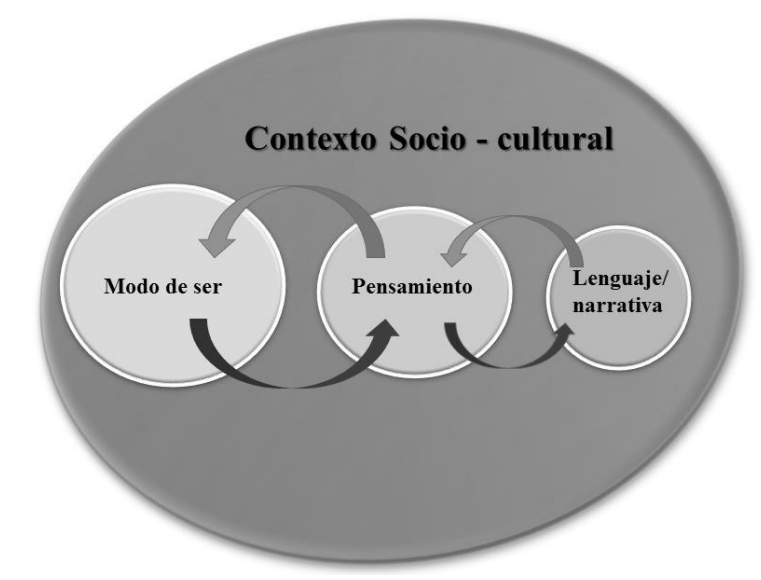

Fuente: Elaboración propia

\section{RESULTADOS}

El análisis de las experiencias de hombres y mujeres a través de la narrativa ha permitido los siguientes hallazgos:

\subsection{Conceptualización del piropo}

Etimológicamente la palabra piropo proviene del latín pyropus que a su vez deriva del griego pyrôpos, originalmente significaba una variedad de granate, de color rojo fuego, mиy apreciada como piedra fina (Preisig, 1998: 5). El piropo alguna vez usó símiles para denotar la belleza femenina, siendo el mensaje un granate con el poder de hacer sonrojar a las mujeres objeto del piropo. Esta apreciación positiva da la impresión del surgimiento del piropo como expresión de aprecio hacia lo considerado estético. Sin embargo, la definición refleja contradicciones ya que, en el imaginario colectivo, se lo relaciona como un halago, pero al momento de contrastarlo con la narrativa de experiencias, la realidad denota que el halago desaparece, dando paso al rechazo al piropo.

Para fines de esta investigación, definimos al piropo como un acto de habla construido a través de la objetivización de la mujer, reflejando en el acto del piropeador - más allá de transmitir un comentario y aún más de hacer notar su fijación o deseo - la invasión y 
dominio de la persona receptora del mensaje y del espacio público de quien se atribuye el derecho de violentar a otra persona por su sexualidad y cuerpo, siendo la violentada generalmente mujer. Consideramos que, aun tomando al piropo ya sea como halago u ofensa - tanto desde quien lo emite como desde quien recibe el comentario -, ambos están relacionados a la invasión de un espacio ajeno; la diferencia se basa únicamente en el empleo del lenguaje para disfrazar la verdadera intencionalidad. Todo piropo tiene como objetivo principal el campo de dominio de quien lo profesa; si tal intención no fuese cierta, el piropo no se materializaría a través de esta práctica que denota relaciones de género.

\subsection{Lingüístico: connotaciones del piropo}

Todo acto de habla utiliza códigos para la comprensión del mensaje hacia su destinatario, en tal sentido, el piropo contiene figuras femeninas y masculinas que están ocultas en la palabra. Así mismo, su utilización no viene a ser accidental ni sufre una suerte de ocurrencia o jocosidad, al contrario, el ser humano, más allá de ser o no consciente del trasfondo, utiliza códigos lingüísticos en tanto pretende expresar significaciones concretas.

Al respecto, dentro de las palabras de mayor uso para efectuar el piropo, están las figuras de la mujer como:

(1) Mamita, mamacita; íntimamente relacionada al rol asignado a la mujer debido a la capacidad biológica de gestar. La maternidad concebida como propósito de vida forma parte de la concepción femenina en sociedades conservadoras en donde se prepondera a la mujer en base a la consecución de tal mandato.

(2) Reina o diosa, respectivo a una figura imposible de alcanzar, distante pero deseada, además de la connotación de reina hacia la mujer como quien debe conquistar lo privado, el hogar.

(3) La infantilización de la mujer a través de sustantivos como niña o bebé, bien pueden sugerir ternura, inocencia, cuidado e incluso inmadurez desde lo corpóreo y la actitud que refleja la mujer al caminar. Sin embargo, la niñez también está relacionada con vulnerabilidad. Dentro de esta figura intervienen muchos aspectos de mayor complejidad, como la edad de la mujer objeto del piropo y los adjetivos y demás sustantivos utilizados en el acto del habla. Si se trata de adolescentes, la figura de la niña roza el límite de lo prohibido, jugando con temas socialmente censurados, puede pasar fácilmente de ser un recurso de respeto hacia alguien menor a ser un recurso que guarda dentro de sí represiones generadas por el gusto a lo infantil, a la niñez.

(4) La muñeca como figura femenina aludida en el piropo denota la importancia que la sociedad cruceña le atañe a la corporalidad femenina asociada con un canon de belleza específico. El estereotipo de la mujer con cuerpo de muñeca obedece al modelo físico femenino difundido desde la industria del modelaje y los mass media. La obsesión femenina por ser la muñeca de medidas perfectas forma parte de los estereotipos cruceños; la mujer que posee tales formas es admirada de sobremanera y es un objeto de deseo tanto masculino como femenino.

(5) La compañía femenina como sinónimo de no intimidación es una figura que representa de sobremanera la concepción femenina y masculina dentro del piropo. La compañía femenina no es concebida como sinónimo de respeto en espacios públicos, pues se evoca a que la mujer debe estar al lado de un par masculino para ser respetada, caso contrario, está en calidad de disponible o desprotegida. La cantidad y edad de las mujeres es indiferente, pudiendo transitar sola o con un grupo de cuatro mujeres.

Dentro de los piropos también se denotan figuras masculinas desde la palabra, en tanto se posicionan como agentes activos: 
(1) El hombre como hacedor, referido al accionar masculino que manifiesta deseos desde el acto de habla. Se expresa entonces la voluntad masculina a través del mensaje, pues se erige desde lo que se considera de fácil acceso, lo que puede ser potencialmente suyo. La visión del hombre como quien satisface sus pulsiones y, más que ello, su volición invasiva a través de la palabra es la que trasluce el poder masculino en el lenguaje.

(2) La compañía masculina: cuñado o socio, ambas relacionadas a una complicidad y solidaridad entre el emisor del mensaje y el acompañante. Esta figura representa la ausencia de cualidades masculinas para quien piropea, por lo cual no es considerado rival. Dentro de las interacciones masculinas de la vida cotidiana, se teme y/o respeta a quien tiene mayores semejanzas al prototipo de hombre varonil. En este sentido, ambos calificativos desconocen tales atributos, por lo cual el piropo es fácilmente expresado.

(3) Uso de determinantes posesivos para expresar el acto de habla. Como se habría expresado en líneas anteriores, la utilización de ciertas palabras no es cuestión accidental, sino que refleja modos de ser encriptados en esquemas de pensamiento. Los determinantes reflejan el deseo de dominio a través de la palabra, desde lo que se considera propio o suyo. "Mi" como determinante, por ejemplo, en un piropo denota cercanía y posesión, relacionamiento mutuo, cosa totalmente contraria entre dos personas que no se conocen. Los determinantes posesivos denotan la pertenencia de la cosa o persona por parte de quien habla. En el sentido de los piropos, existen muchas formas de expresar interés, pudiendo utilizar el lenguaje desde una forma menos posesiva, pero en el pensar masculino se puede llegar a admirar un cuerpo femenino como también a desearlo y poseerlo.

Como se puede evidenciar, tales denominaciones o sustantivos son figuras que reflejan más de lo que cree decirse, pues denotan estructuras de pensamiento (Lacan, 2004) de quienes ejercen el control tanto de la situación como de los cuerpos objetivados a través de la palabra, en contextos públicos como la calle. Efectivamente, los sustantivos utilizados en tales actos de habla sumados a los determinantes, son manifestaciones de la concepción que se tiene hacia ambos géneros. Estas acciones de dominio masculino suelen pasar desapercibidas en nuestro andar cotidiano, empero, forman parte activa de la realidad cruceña en espacios de amplio tránsito como la calle.

\subsection{Experiencia: análisis de las significaciones de hombres y mujeres hacia el piropo}

La vida cotidiana está fuertemente imbuida por significaciones y re-significaciones desde quienes conforman e interactúan en lo que llamamos sociedad. El análisis de las vivencias permite comprender cómo se asimila este hecho en ambos géneros, su repercusión en las interacciones diarias, y trascendencia a lo largo del tiempo.

\subsubsection{Visión genérica y generacional del piropo en espacios públicos}

En el piropo existen dos percepciones, (1) la concepción del piropo en espacios públicos visto como un halago y (2) como un insulto u ofensa. La visión positiva del acto de habla proviene de generaciones más adultas, tanto masculinas como femeninas, catalogándolo como lisonja en tanto se utilicen palabras denominadas galantes:

N1: "Si el piropo no es ofensivo para mi es un halago... Si es bueno levanta mi autoestima me hace sentir que estoy bonita que estoy bien, que soy atractiva". Selenia, 45 años $(25 / 09 / 2014)$

N2: "El piropo no es más que una muestra de admiración, de amor, de inquietudo de atracción física hacia una mujer”. Jorge, 53 años (25/09/2014) 
La diferencia de apreciación entre mujeres jóvenes y maduras tiene un matiz distinto, las mujeres maduras le atribuyen un carácter polisémico debido a experiencias anteriores y actuales en espacios públicos. Los piropos galantes están atribuidos a las cualidades positivas de la cortesía masculina, posee tal significación, debido a las vivencias de la juventud.

La visión de las mujeres jóvenes está fuertemente influida por la negatividad hacia el acto de habla. Las significaciones al piropo son negativas por las experiencias vividas y narradas sobre la interacción en la calle, además de comparadas con las experiencias de sus antecesoras. En la actualidad tanto mujeres jóvenes como adultas reciben piropos considerados desagradables por parte de desconocidos.

\subsubsection{Significación del cuerpo femenino}

Desde la externalidad, el piropo como acto de habla, insinúa ser deseo sexual o atracción física materializada a través de la palabra. Sin embargo, más allá de lo evidente, este acto es invasivo y expresa el campo de dominio del hombre sobre la mujer, la apropiación del espacio y el juego del poder. El esquema de pensamiento de trasfondo del piropo es la concepción del cuerpo femenino como espacio disponible a invasión a través de la palabra y los gestos, naturalizando los modos de ser inter- genéricos cargados de violencia.

N3: "Te están definiendo como algo que sós una cosa que tiene tetas que tiene no sé, que te estás manejando por la calle es para exhibirte y si a ellos les gustás entonces ellos tienen derecho de decirte que les gustaste...que algo les gusta de vos". Cecilia, 25 años (25/09/2014)

\subsubsection{La calle como sinónimo de inseguridad y los nuevos espacios de interacción}

La calle es un espacio de amplio tránsito que ha adquirido nuevas significaciones en relación al crecimiento poblacional y las coyunturas ligadas a la seguridad de transeúntes. Generalmente está vinculada con la sensación de inseguridad debido a la tasa de criminalidad y percepción de desconfianza generada hacia el extraño. Es imprescindible tener presente que la sociedad cruceña desconfía del desconocido; en lugares de amplio tránsito, los niveles de temor y amenaza sentidos frente a un extraño son considerables.

N5: "No ya no se puede, veo un peligro muy constante para la mujer ya no hay confianza ni en personas mayores, ya no hay”. Faustino, 60 años (15/10/2014)

$\mathrm{Si}$ el espacio que es de uso masivo e indiscriminado conocido como calle genera desconfianza y temor tanto en hombres como mujeres, es de esperarse que las conductas de ambas partes estén relacionadas con la precaución y la susceptibilidad constante. La población femenina la significa como un espacio generador de temor, en tal caso las palabras proferidas por el extraño no serán bien recibidas.

La relación de la calle con la interacción entre géneros o seducción ha sufrido una modificación bastante interesante debido al crecimiento de la ciudad y la amalgama de lugares de esparcimiento. La ciudad cruceña posee hoy diferentes espacios físicos o virtuales: las redes sociales y lugares públicos como boliches, cafés y demás tienen esta cualidad abierta a la interacción entre personas.

N6: "En teoría hasta un hombre siente de que no está haciendo nada malo porque...es verdad uno va a divertirse a los boliches pero el segundo efecto es que uno va a un boliche a conquistar". Antonio, 24 años (16/10/2014)

N7: "Yo quiero conocer a alguien y me voy a un bar porque es un lugar para conocer amigos, para instalar charla o por último le dice: mire yo quiero ser un amigo más. Pero con un piropo... a no ser que después que le piropeen le comience a 
hablar caminando, eso es peligroso porque no sabe qué reacción va a tener si es en la calle”. Jacquelín, 46 años (16/10/2014)

\subsubsection{Diferenciación temporal: piropo de antaño y piropo actual}

La percepción del piropo a través del tiempo es un componente muy dialogado entre personas de edad adulta y adulta mayor. Desde el discurso social las épocas pasadas tienen mejor cabida por los niveles axiológicos relacionados con las tradiciones, la denotación del respeto y el cuidado de relacionamiento entre géneros. Es así que el piropo de antaño pasa por la concepción del respeto. En la Santa Cruz campanario, la sociedad entera se conocía y no podían existir desfases en el trato entre géneros, pues existían mecanismos de coerción y control. Quien tenía algún interés en interactuar con el género opuesto debía de cuidar las formas del lenguaje, pues aquella era una sociedad represiva y conservadora, en donde el ser y honra femenina eran sobrevaloradas.

La visión del hombre respetuoso y la mujer de cuidadoso trato y vestimenta responden a los mecanismos de represión de comportamientos en lugares públicos como la calle, en tal escenario y bajo esas condiciones, ésta podía fungir como un espacio de relacionamiento vigilado por personas mayores con potestad de amonestación.

N7: "Eran más respetuosos, no se extralimitaba la gente porque inclusive si vos eras corteja besarse en la calle era pecado capital, venía un viejo y te trataba y vos te sentías sucia. Esas cosas no se podían”. Adela, 53 años (12/08/2014)

N8: "Hasta la década del 70 era muy lindo, las chicas se veían que salían con trajes de... porque antes nosotros teníamos esa costumbre de molestar: está saliendo con su traje dominguero... porque antes los domingos se vestían bonitas y eso les causaba chiste y nosotros también inventábamos muchas cosas para hablar, pero nunca había un sobrepase de palabras, si a ellas no les gustaba algo... preferible era retirarse, por qué le digo eso porque Santa Cruz era chico antes a veces en algún lugar nos volvíamos a encontrar ... ". Faustino, 60 años (15/10/2014)

Sin embargo, en la actualidad, el súbito crecimiento de la ciudad ha dejado de lado a la Santa Cruz campanario, dando paso a la paulatina desaparición de tales mecanismos de represión. A su vez, las nuevas generaciones califican al piropo como una ofensa, un comentario inoportuno o desagradable. Finalmente, las personas han optado por otros espacios para relacionarse y las conversaciones espontáneas en espacios como la calle, han disminuido considerablemente por el miedo al extraño.

N9: "El actual no lo veo que es igual ya, ha cambiado, se ha perdido esa tradición. Ahora ya no es piropo, lo que lanzan ahora son malcriadeces, palabras fuertes le dicen a las chicas como si las conocieran, como si fueran algo de ellas, eso de mi parte me duele escuchar eso". Faustino (15/10/2014)

N10: “... ahora que te digan: qué chica más linda y te deshagan con la mirada... puede que sean los mismos piropos de antes pero no lo están diciendo de la misma forma, no están sintiendo lo mismo”. Daniela (10/10/2014)

\subsubsection{Motivaciones}

Gracias al análisis de experiencias, se ha podido evidenciar que la motivación de emitir un piropo en espacios como la calle no es necesariamente la de halagar a otra persona, van más allá del supuesto cultural de halago hacia la mujer bella o atractiva. Las motivaciones para piropear encontradas son: (1) Tener cuerpo femenino, ser mujer. La motivación principal es 
la invasión al cuerpo femenino. Si bien las mujeres entrevistadas identifican al acto como una expresión de deseo sexual, debemos acotar que tal significación es lo aparente, pues a primera vista pareciese que la intención es el desahogo sexual, cuando en realidad se trata del ejercicio de poder hacia lo considerado inferior. (2) Motivación a la antigua, búsqueda de halagar o conquistar a una mujer. El hombre conquistador sondea a las mujeres que le interesan y es a través del piropo que lanza el anzuelo para hacer notar su interés y fijación, aunque, ésta motivación pueda ser rechazada por la aludida.

N11: "Depende de cuál sea la intención del que piropea, porque el que piropea puede tener varias intenciones: puede tener la intención de cortejar a una mujer, puede ser la intención de sacar, de desahogar la excitación que tiene, puede ser para hacer la joda y que se rían sus amigos también”. Juan Pablo (10/09/2014)

(3) La tercera motivación es la burla. El piropo actúa como mecanismo de broma entre compañeros a través de una frase construida gracias a la complicidad grupal. La burla surge por la observación de cuerpos considerados no atrayentes o marchitos, ya sea por la edad, medidas o contextura femenina.

N12: "Primero era como una forma de divertirse porque digamos estábamos en la construcción y de un rato a otro pasaba una mujer digamos una pelada y... el tipo agarraba y le lanzaba algún piropo que le cause gracia al resto que estaba ahí... no tanto para atraer a la chica ... sino para joder un rato entre ellos”. Iván (16/10/2014)

\section{MODO DE SER CRUCEÑO}

Gracias a las experiencias brindadas por hombres y mujeres en lo concerniente a significaciones del acto de habla como a piropos per sé, se ha podido descifrar, más allá del pensamiento expresado a través de la palabra, el modo de ser de la sociedad cruceña, detallados a continuación:

\subsection{El ejercicio de poder a través del modo de ser masculino como sinónimo de pulsiones y animalidad}

Dentro de la narrativa femenina se relaciona al piropo con la necesidad de descarga sexual masculina, tal aseveración es una evidencia o prenoción que se maneja en la vida cotidiana con total naturalidad:

N13: "Los hombres para mí son seres sexuales y la mayoría del tiempo paran pensando en eso, se imaginan eso...”. Daniela, 22 años (10/10/2014)

La relación entre la naturalidad masculina ligada al desahogo del deseo revela un modo de ser culturalmente aceptado, el ser macho y realizar actos invasivos. Cuando se considera al ser masculino como pulsión pura se acepta que tal condición es natural, siguiendo con el ciclo de legitimación de ese modo de ser. La construcción del ser masculino en una sociedad patriarcal se basa en la prenoción de una sexualidad activa y despótica. La manifestación masculina de deseos con total libertad en la calle es el síntoma de los comportamientos arbitrarios aceptados socialmente a favor de quien posee los rasgos del opresor.

El ejercicio de poder reflejado en el piropo es el mismo acaecido en las esferas públicas y privadas. Existe una relación desigual entre quien se considera superior -quien maneja instituciones públicas, quien ejerce cargos públicos, quien cree poseer mayor capital económico, etc.-; en desmedro del considerado inferior o inexistente. Lo importante aquí es 
asumir las características del opresor y naturalizarlas para el logro de sus fines. Tal modo de ser puede ser avalado y practicado por ambos géneros; desplegando así lo que Bourdieu define como hábitus (Bourdieu, 1995).

\subsection{La condescendencia femenina frente a un acto de habla invasivo}

La condescendencia femenina se materializa en la aceptación del piropo como sinónimo de halago, en donde la figura dominante del hombre es aceptada y axiológicamente valorada como correcta. Desde la estructura del ser femenino se juega mucho con el beneplácito hacia el hombre que cumple con los estándares del ser viril o macho, aceptando comportamientos masculinos agresivos en contra de la mujer e incluso culpabilizándose ella o a su mismo género por tales actos.

El encubrimiento femenino hacia este modo de ser es el reflejo de la internalización de lo construido socialmente en la cultura cruceña. Por tal normalización es que no es extraño escuchar a mujeres acusar a quienes han sido objeto de tocamientos en lugares públicos, violaciones o feminicidios; a través de diferentes excusas. En espacios televisivos se observa el refuerzo hacia actitudes consideradas masculinas por medio de la posesión o acercamiento de mujeres, pues quien demuestra tales comportamientos es vitoreado y rodeado por las mismas.

La sociedad en sí tiene distintos mecanismos de reproducción de nociones culturales, desde las esferas privadas en donde se enseñan los patrones socioculturales y axiológicos como lo es la familia, hasta espacios masivos de comunicación e interrelación humana. Si bien dentro de las entrevistas realizadas la tendencia encontrada es hacia la desaprobación del piropo y su relacionamiento con la invasión, no podemos ignorar la existencia de mujeres que aprueban tales comportamientos. Respuestas como: sentirse linda, deseada o atractiva forman parte del consentimiento hacia un modo de ser invasor del cuerpo femenino, y más que ello, al ser en sí mismo.

\subsection{El piropo: reflejo subjetivo de hechos objetivos violentos}

Cuando el ejercicio de poder es avalado a través de actos invasivos como el piropo, la sociedad construida en base al dominio del más fuerte deja libre espacios de opresión mucho más directos. Si la sociedad cruceña considera al piropo como parte de la idiosincrasia, no es de esperar la inoperancia y miopía social ante como son los tocamientos en lugares públicos hacia desconocidas, además de violaciones y feminicidios.

La permisividad social hacia la expresión del piropo refleja la naturalización de la opresión femenina en pos de una supremacía que prepondera el modo de ser considerado como masculino. En tal sentido, existe una estrecha relación entre el piropo como expresión subjetiva de invasión y los hechos objetivos mencionados, en donde se refleja la concepción femenina como un espacio a ser usurpado, tocado y violentado en espacios públicos.

En la sociedad cruceña existen problemas serios relacionados con la violencia hacia las mujeres, no resueltos gracias a la concepción social del hecho como una cuestión aislada. $\mathrm{Si}$ se prepondera un modo de ser dominante e invasor, no es de extrañarse la aparición diaria de hechos misóginos en espacios públicos y privados retratados por medios de comunicación de forma grotesca.

Los esquemas de pensamiento, construidos gracias a este modo de ser, se reflejan en la sociedad cruceña y boliviana desde distintos ámbitos. Por ejemplo, el ejercicio de poder no contempla niveles de diálogo ni minorías, no es racional sino primitivo, unilateral, totalitario, subyugante y principalmente masculino (Simmel, 1930: 13). En tal sentido, si la praxis política está orientada por el modo de ser imperante, la sociedad deja pasar comportamientos 
agresivos desde las mismas autoridades. Un presidente puede agredir y mofarse de mujeres con o sin cargos públicos, un alcalde puede tocar cuerpos ajenos sin ninguna reprobación. Además, personas con cargos públicos cometen vejaciones o emiten comentarios sobre cuerpos femeninos, emiten juicios sobre cómo deben manejarse las mujeres en términos de su moral y fertilidad. El cuerpo femenino parece ser un bien público mancillado por acciones violentas y subyugantes desde las mismas autoridades que deberían garantizar una vida libre y segura para la población en general. Desde las esferas de gobierno y la sociedad se naturaliza la violencia sobre el otro, eso crea y expresa modos de pensamiento y de ser fundados en una sociedad hecha desde y para la violencia.

\section{CONCLUSIÓN}

Con el presente estudio, se puede constatar que el piropo es un artefacto cultural que puede ser de amplio análisis desde la sociología y el estudio del lenguaje. Es, principalmente, un medio de comprensión de lo que la sociedad cruceña ha construido en el paso del tiempo. La categoría fenomenológica de modos de ser, da cuenta de la construcción axiológica que la sociedad cruceña ha internalizado respecto al actuar masculino y femenino. Refleja una dinámica social y genérica ligada a la violencia e invasión hacia quien se considera débil o en desventaja. Los espacios públicos son escenarios en donde se ejerce dominio producto de tal modo de ser, reflejado a través de la narrativa de hombres y mujeres. El piropo es un hecho de la vida cotidiana, aparentemente subjetivo, que materializa tal modo de ser, es decir, denota la permisividad cultural hacia el ejercicio de poder.

\section{BIBLIOGRAFÍA}

Berger, P. y Luckmann, T. (2001) La Construcción Social de la Realidad. Buenos Aires, Argentina: Amorrortu Editores.

Bourdieu, P. (1995) Las reglas del arte: génesis y estructura del campo literario. México: Anagrama.

Gaytán Sánchez, P. (2009) Del piropo al desencanto. Un estudio sociológico. México: Universidad Autónoma Metropolitana.

Habermas, J. (1999) Teoría de la Acción Comunicativa I. Racionalidad de la acción y racionalización social. España: Taurus.

Lacan, J. (2004) La práctica analítica. Bueno Aires: Paidós.

Lagarde, M. (2005) Los cautiverios de las Mujeres. Madresposas, monjas, putas, presas y locas. México: Universidad Nacional Autónoma de México.

Malaver, I. y Gonzáles, C. (2008) "El antipiropo: el lado oculto de la cortesía verbal”. En A. Briz, A. Hidalgo, M. Albelda y J. H. Contreras (Eds.) III Coloquio Internacional "Cortesía y conversación: de lo escito a lo oral", Valencia, pp. 267-283.

Merleau - Ponty, M. (1993) Fenomenología de la Percepción. Barcelona: Planeta-Agostini.

Ricoeur, P. (1990) Freud: Una Interpretación de la Cultura. México: Siglo Veintiuno Editores.

Ricoeur, P. (2010) Del texto a la acción. Ensayos de Hermenéutica II. Buenos Aires, Argentina: Fonde de Cultura Económica.

Schutz, A. (1972) Fenomenología del Mundo Social: Introducción a la Sociología Comprensiva. Buenos Aires, Argentina: Paidós.

Searle, J. (1969) Actos de Habla: Ensayo de Filosofía del Lenguaje. Buenos Aires, Argentina: Planeta Agostini. 
Seco, R. (21 de Marzo de 2011) "Lento Adiós al piropo". El País. Accesible en https://goo.gl/mMwGei (consulta, 15/2/2017).

Simmel, G. (1930) Cultura Femenina y Otros Ensayos. Madrid: Revista de Occidente.

Wittgenstein, L. (1988) Investigaciones Filosóficas. Philosophische Untersuchungen. Barcelona: Crítica

\section{Breve currículo:}

\section{Paula Fernanda Lino Maldonado}

Licenciada por excelencia en Sociología por la Universidad Autónoma Gabriel René Moreno, Santa Cruz Bolivia. Experiencia relacionada en: planificación estratégica y académica con instituciones privadas, planificación integral para el desarrollo con instituciones públicas; asesoría, edición y desarrollo de trabajos de investigación en ciencias sociales; y elaboración de proyectos educativos a nivel postgrado para disciplinas de ciencias sociales. 